\title{
Liver cancer mortality trends in South Africa: 1999-2015
}

\author{
Daniel Mak ${ }^{1}$, Mazvita Sengayi ${ }^{2,3}$, Wenlong C. Chen ${ }^{2,5}$, Chantal Babb de Villiers ${ }^{4}$, Elvira Singh ${ }^{2,3^{*}}$ \\ and Anna Kramvis ${ }^{1 *}$ (D)
}

\begin{abstract}
Background: In South Africa (SA), liver cancer (LC) is a public health problem and information is limited.

Methods: Joinpoint regression analysis was computed for the most recent LC mortality data from Statistics South Africa (StatsSA), by age group, sex and population group. The mortality-to-incidence ratios (MIRs) were calculated as the age-adjusted mortality rate divided by the age-adjusted incidence rate.

Results: From 1999 to 2015, the overall LC mortality significantly decreased in men (-4.9\%) and women (-2.7\%). Overall a significant decrease was noted in black African men aged 20-29 and 40-49 years, and white women older than 60 years but mortality rates increased among 50-59 and 60-69 year old black African men (from 2010/2009-2015) and women (from 2004/2009-2015). The mortality rates increased with age, and were higher among blacks Africans compared to whites in all age groups - with a peak black African-to-white mortality rate ratio of six in men and three in women at ages 30-39 years. The average MIR for black African men and women was 4 and 3.3 respectively, and 2.2 and 1.8 in their white counterparts. Moreover, decreasing LC mortality rates among younger and the increase in rates in older black Africans suggest that the nadir of the disease may be near or may have passed.

Conclusions: Findings of population-age subgroup variations in LC mortality and the number of underdiagnosed cases can inform surveillance efforts, while more extensive investigations of the aetiological risk factors are needed. Impact: There was a large race, sex and age differences in trends of LC mortality in SA. These findings should inform more extensive evaluation of the aetiology and risk factors of $L C$ in the country in order to guide control efforts.
\end{abstract}

Keywords: Liver cancer, Trends, Mortality, Incidence, South Africa, Sub-Saharan Africa

\section{Background}

Liver cancer (LC) is the second largest contributor to cancer mortality worldwide [1], with 810,000 LC deaths recorded in 2015 [2]. The most common type of LC globally is hepatocellular carcinoma ( $\mathrm{HCC})$, accounting for 75 to $90 \%$ of primary LCs, followed by cholangiocarcinoma [3]. In 2015, close to 20.5 million years of healthy life [disability-adjusted life-years (DALYs)] were lost as a result of this cancer and thus it remains an important public health issue worldwide [2].

\footnotetext{
* Correspondence: Elvira.Singh@nhls.ac.za; Anna.Kramvis@wits.ac.za ${ }^{2}$ National Cancer Registry, National Health Laboratory Service, Johannesburg, South Africa

${ }^{1}$ Hepatitis Virus Diversity Research Unit (HVDRU), Department of Internal Medicine, School of Clinical Medicine, Faculty of Health Sciences, University of Witwatersrand, Johannesburg, South Africa

Full list of author information is available at the end of the article
}

In the United States, population group disparities in LC mortality have been reported, with higher rates among African American young adults (35-49 years) and older ages (50-64 years) (2.0 and 18.6/100,000, respectively) compared to Whites (0.9 and 7.7/100,000, respectively) [4]. Invariably, African-to-white American mortality rate ratios are $>1$ in both men (1.7) and women (1.4) [5]. Declining LC mortality rates have been reported in young African and white Americans (5.3 and $2.8 \%$ annually, respectively) while those of older ages are increasing (by 6.2 and $6.3 \%$ annually, respectively). In America, Africans are more frequently diagnosed with LC at a younger age than Whites [6]. The former have larger tumour size, more advanced tumour stage/with metastatic disease, lower levels of alpha-fetoprotein and are least likely to present with cirrhosis [7, 8]. Reasons for these disparities have been attributed to differences

(c) The Author(s). 2018 Open Access This article is distributed under the terms of the Creative Commons Attribution 4.0 International License (http://creativecommons.org/licenses/by/4.0/), which permits unrestricted use, distribution, and reproduction in any medium, provided you give appropriate credit to the original author(s) and the source, provide a link to the Creative Commons license, and indicate if changes were made. The Creative Commons Public Domain Dedication waiver (http://creativecommons.org/publicdomain/zero/1.0/) applies to the data made available in this article, unless otherwise stated. 
in the prevalence of major risk factors including hepatitis $\mathrm{B}$ and/or $\mathrm{C}$ virus (HBV/HCV), obesity and diabetes [9], and to some degree, because of barriers to accessing high-quality care [10].

In contrast, data on LC mortality in South Africa (SA), and most regions of sub-Saharan Africa, are limited. The International Agency for Research on Cancer GLOBOCAN estimated 37,353 LC deaths occurred in this subcontinent in 2012 and predicted this number to increase to 64,525 by 2030 [1]. Thus, the present study aims to delineate the patterns and temporal trends of LC mortality in SA, based on currently available data from the national death registry from 1999 to 2015 by sex, age and population group.

\section{Methods}

\section{Data sources and selection criteria}

Cause of death was based on death certificate information reported to Statistics South Africa (StatsSA), a national statistical service that compiles routine mortality statistics based on medical certification of the cause of death registered with the Department of Home Affairs (DHA). LC (C22.0), as the first or underlying cause of death was selected according the ICD-10 for the period of 1999 to 2015. Analyses were restricted to four large population groups that were defined according to the SA National Census as Black Africans, White, Coloured (mixed ancestry) and Indian/Asian [11]. In 2015, each population group accounted for $80.5,8.3,8.8$ and $2.5 \%$ of the SA population, respectively [12]. Since the majority of cases reported each year for the Coloured and Indian/Asian populations were fewer than 100, both these groups were excluded from further analysis.

\section{Statistical analysis}

Age-standardized incidence rates (ASIRs) and mortality rates (ASMRs) per 100,000 persons were calculated using mid-year population estimates provided by StatsSA and by direct standardization with the Segi's World Standard Population (1960) [13], by population group, sex and age group (summarized into 10-year age groups: $20-29,30-39,40-49,50-59,60-69$ and $70+$ years). Joinpoint regression trends were examined by population group, sex and age groups, based on a two joinpoint segment model [14]. Based on the criteria used in the National Cancer Institute's Cancer Trends Progress Report [15] and modified in a published report by Altekruse et al. [4], the trends were described as annual percentage change (APC) and categorized into five groups: 1: Significant decrease (APC $<0 \%, p<0.05)$; 2 : Non-significant decrease (APC $<-0.5 \%, p>0.05)$; 3 : Stable (Absolute value of rate change less than or equal to $0.5 \%$ per year, $p>0.05)$; 4 : Non-significant increase (APC $>+0.5 \%$ per year, $p>0.05$ ); and 5: Significant increase (APC $>0 \%, p<0.05)$. The APC and average annual percentage change (AAPC) were calculated using Joinpoint software (Version 4.5.0.1) from the Surveillance Research Program of the US National Cancer Institute [16]. Statistical significance was taken at $p \leq 0.05$. The mortality-to-incidence ratios (MIRs) were calculated as the age-adjusted mortality rate divided by the age-adjusted incidence rate for LC from 1999 to 2012, and was used to compare population group and sex disparities. Age-Adjusted incidence rates for MI ratios were derived from the South African National Cancer Registry's pathology-based cancer surveillance system.

\section{Results}

Figure 1 shows the sex and population group-specific overall ASMR for LC in SA. The results of the joinpoint regression analysis, the APCs for each trend, and the AAPCs in both genders are depicted in Table 1. During the 17-year mortality study period, a total of 27,791 deaths from LC were reported. Of the total cases of known population group $(22,435,81 \%)$, majority were men (62.1\%) and black African (73.2\% vs $15.4 \%$ whites). Women died of LC at significantly older ages than men, with $83.5 \%$ versus $79.1 \%$ being older than 40 years, and $59.6 \%$ versus $50.1 \%$ being older than 60 years, respectively. LC ASMRs in men and women (overall) did not significantly change throughout the study period (5.3 and 2.1/100,000 in 1999 to 5.4 and 2.5/100,000 in 2015), with an AAPC of 0.3 and $0.8 \%(p>0.05)$ respectively. The segmented joinpoint analysis identified a period of decrease in mortality rates (men: 2004-2009, APC of $-4.9 \%$; women: 2002-2009, APC of $-2.7 \%$ ), after which the rates began to increase (2009-2015, APCs: 3.4 and 2.6\% respectively). In men, age-group analysis revealed that, during the entire study period, the mortality rates decreased significantly for all age groups $>20$ years old; whereas in women this only included 40-49 and >60 year olds. However, segmented joinpoint analysis by age groups distinguished between two different time periods, i.e. an initial period characterized by a significant decrease in $50-59$ year old men (1999-2010) and 60-69 year old women (1999-2009), and a second period with an increase or levelling-off in rates until 2015.

Over the study period, population group analysis showed that black African men $(6.2 / 100,000)$ had the highest LC ASMR, followed by white men $(4.5 / 100,000)$, black African women $(3.1 / 100,000)$ and white women $(1.8 / 100,000)$ (Fig. 1). The corresponding black African-to-white LC mortality rate ratio increased and peaked at ages 30-39 years (6-fold in men and 3-fold in women), but decreased thereafter to around 1.0 in those $>70$ years old in both sexes (Fig. 2). Segmented joinpoint analyses of population-age subgroups by sex are shown in Table 2. In black Africans, a decreasing or stable trend in ASMRs was observed among 


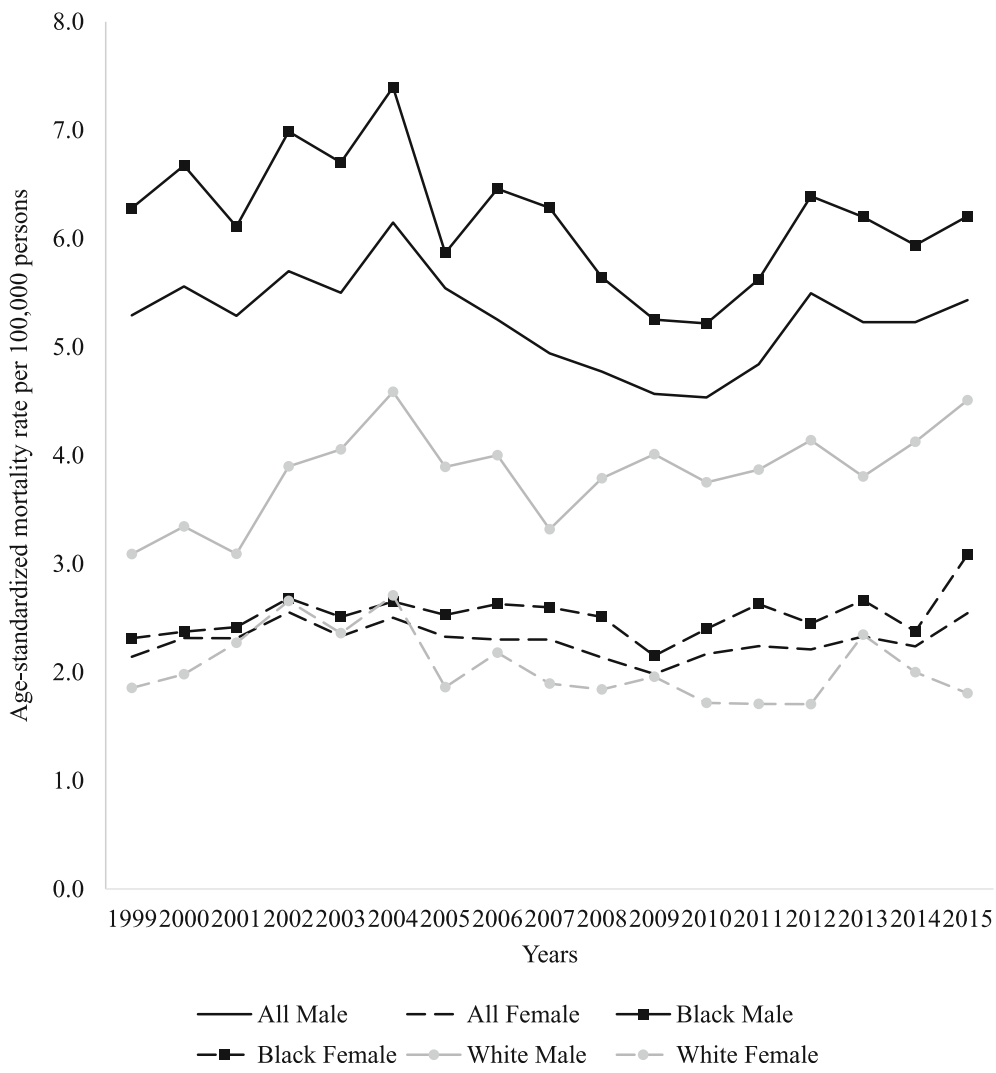

Fig. 1 Liver cancer age-standardized mortality rates in South Africa by population group and sex, 1999-2015

Table 1 Joinpoint analysis of age-standardised liver cancer mortality rates by sex and age group in South Africa; 1999-2015

\begin{tabular}{|c|c|c|c|c|c|c|c|}
\hline \multirow{2}{*}{$\begin{array}{l}\text { All } \\
\text { Age (Years) }\end{array}$} & \multirow[b]{2}{*}{$\operatorname{AAPC}(95 \% \mathrm{CI})$} & \multicolumn{2}{|l|}{ Trend 1} & \multicolumn{2}{|l|}{ Trend 2} & \multicolumn{2}{|l|}{ Trend 3} \\
\hline & & Range of Years & APC & Range of Years & APC & Range of Years & APC \\
\hline \multicolumn{8}{|l|}{ Men } \\
\hline Overall & $0.3(-1.2,1.8)$ & 1999-2004 & $2.1(-0.7,5)$ & 2004-2009 & $-4.9^{*}(-8.6,-1.1)$ & 2009-2015 & $3.4^{*}(1.2,5.6)$ \\
\hline $20-29$ & $-3.2^{*}(-4.9,-1.4)$ & 1999-2015 & $-3.2^{*}(-4.9,-1.4)$ & & & & \\
\hline $30-39$ & $-1.8^{*}(-3,-0.6)$ & 1999-2015 & $-1.8^{*}(-3,-0.6)$ & & & & \\
\hline $40-49$ & $-2.1^{*}(-3.2,-1.1)$ & 1999-2015 & $-2.1^{*}(-3.2,-1.1)$ & & & & \\
\hline $50-59$ & $-1.8^{*}(-3.3,-0.3)$ & 1999-2010 & $-3.7^{*}(-5,-2.4)$ & 2010-2015 & $2.6(-2,7.3)$ & & \\
\hline $60-69$ & $-3.4^{*}(-4.4,-2.4)$ & 1999-2015 & $-3.4^{*}(-4.4,-2.4)$ & & & & \\
\hline $70+$ & $-2.3^{*}(-3.3,-1.3)$ & 1999-2015 & $-2.3^{*}(-3.3,-1.3)$ & & & & \\
\hline \multicolumn{8}{|l|}{ Women } \\
\hline Overall & $0.8(-0.6,2.2)$ & 1999-2002 & $5.6(-0.6,12.2)$ & 2002-2009 & $-2.7^{*}(-4.7,-0.7)$ & 2009-2015 & $2.6^{*}(0.6,4.8)$ \\
\hline $20-29$ & $-1.5(-3.1,0.1)$ & 1999-2015 & $-1.5(-3.1,0.1)$ & & & & \\
\hline $30-39$ & $-1.4(-3,0.3)$ & 1999-2015 & $-1.4(-3,0.3)$ & & & & \\
\hline $40-49$ & $-1.7^{*}(-2.4,-1)$ & 1999-2015 & $-1.7^{*}(-2.4,-1)$ & & & & \\
\hline $50-59$ & $-0.9(-1.9,0)$ & 1999-2015 & $-0.9(-1.9,0)$ & & & & \\
\hline $60-69$ & $-2.6^{*}(-3.9,-1.3)$ & 1999-2009 & $-4.4^{*}(-5.8,-3)$ & 2009-2015 & $0.5(-2.7,3.7)$ & & \\
\hline $70+$ & $-2.3^{*}(-3,-1.5)$ & 1999-2015 & $-2.3^{*}(-3,-1.5)$ & & & & \\
\hline
\end{tabular}

*The average annual percentage change (AAPC) and/or annual percent change (APC) is statistically significant $(p<0.05)$ 


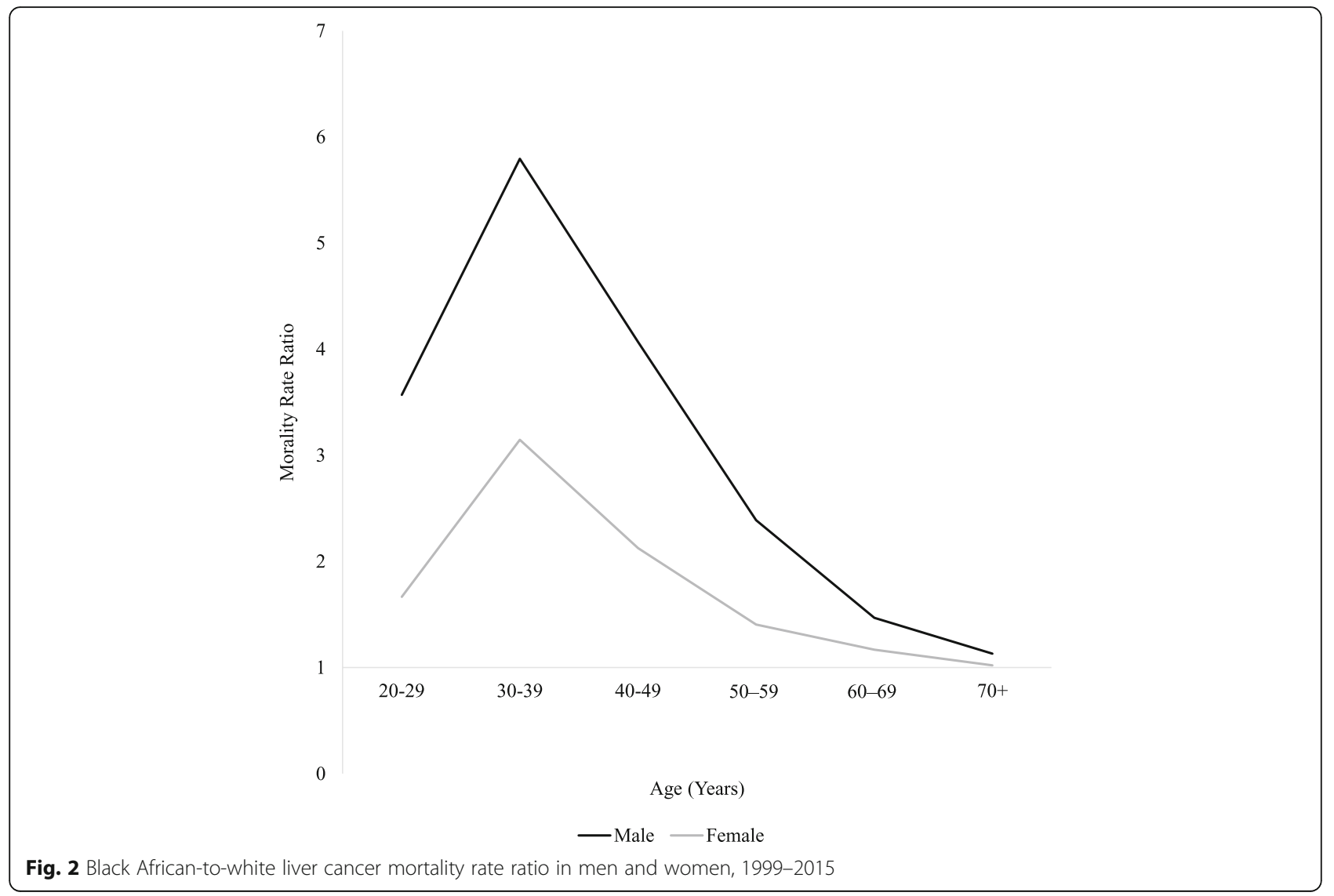

younger ( $<50$ year old) and ( $>70$ year) old men and women from 1999 through 2015. Interestingly, joinpoint analysis identified two different periods for older black Africans (50-59 and 60-69 year old). After an initial period of decreasing ASMRs, a marked non-significant increase was found thereafter in men (5.4 and 2.5\% respectively, $p>0.05$ ), but was significant in women (2.6 and $6.3 \%$ respectively, $p<0.05)$. In whites, age-group analysis revealed that, throughout the entire study period, ASMRs either remained stable (men: 40-69 years; women: 40-49 years) or decreased (men: >70 years; women: $>50$ years). For both the black African and white populations, mortality rates were higher than incidence rates reported to the South African National Cancer Registry, yielding an average MIR of 4 and 3.3 in black African men and women, and 2.2 and 1.8 white men and women (Fig. 3).

\section{Discussion}

The data-set used (from StatsSA) is considered to provide the most comprehensive and representative information on mortality patterns in the country. Our analysis highlights an overall sociodemographic shift in LC mortality in SA over the past two decades. More specifically, there was a shift from a decreasing to an increasing trend in LC mortality among older black Africans (50-69 years). In contrast, mortality trends were stable and decreasing in the white population of the same sex and age groups. Black Africans were more likely to die from LC compared to whites. These racial differences in LC mortality were highest in the 30-39 year old age group with black African-to-white mortality ratios of six in men and three in women. For both the black African and white populations, mortality rates were higher than incidence, yielding an average MIRs of 4 and 3.3 in men and women in the former, and 2.2 and 1.8 in the latter population. Data of most individuals with LC-related deaths were not captured in the South African National Cancer Registry's pathology-based cancer registry. To the best of our knowledge, this is the first such analysis of time trends that demonstrated a LC mortality differential between the black African and white populations by sex nationwide.

In $\mathrm{SA}$, accounting for population-age subgroup disparities in LC mortality is likely multifaceted and may be a consequence of socio-cultural, biological and socioeconomic factors. While the establishment of policies in the mid-1990s dealing with better quality and more accessible health care services may have improved overall patient survival over time [17], and ultimately decreasing mortality as a consequence of increased utilization of 
Table 2 Age-adjusted liver cancer mortality rates joinpoint trends by population group, sex and age group in South Africa; 1999-2015

\begin{tabular}{|c|c|c|c|c|c|c|c|}
\hline \multirow[t]{2}{*}{ Direction } & \multirow[t]{2}{*}{ Sex } & \multirow[t]{2}{*}{ Population Group } & \multirow[t]{2}{*}{ Age, Years } & \multicolumn{2}{|l|}{ Trend 1} & \multicolumn{2}{|l|}{ Trend 2} \\
\hline & & & & Period & APC (95\% Cl) & Period & APC $(95 \% \mathrm{Cl})$ \\
\hline \multicolumn{8}{|c|}{ 1. Significant Decrease } \\
\hline & \multicolumn{7}{|l|}{ Men } \\
\hline & & Black & $20-29$ & 1999-2015 & $-2.3^{*}(-4.2,-0.4)$ & & \\
\hline & & Black & $40-49$ & 1999-2015 & $-1.1^{*}(-2.2,0)$ & & \\
\hline & \multicolumn{7}{|c|}{ Women } \\
\hline & & White & $60-69$ & 1999-2015 & $-2.6^{*}(-4.9,-0.3)$ & & \\
\hline & & White & $70+$ & 1999-2015 & $-3.5^{*}(-4.9,-2.1)$ & & \\
\hline \multicolumn{8}{|c|}{ 2. Non-significant Decrease } \\
\hline & \multirow[t]{2}{*}{ Men } & Black & $70+$ & 1999-2015 & $-1.3(-2.5,0)$ & & \\
\hline & & White & $70+$ & 1999-2015 & $-0.7(-2.2,0.9)$ & & \\
\hline & \multicolumn{7}{|c|}{ Women } \\
\hline & & Black & $20-29$ & 1999-2015 & $-1.5(-4.2,1.4)$ & & \\
\hline & & Black & $40-49$ & 1999-2015 & $-0.9(-2,0.1)$ & & \\
\hline & & White & $50-59$ & 1999-2015 & $-0.9(-3.8,2.1)$ & & \\
\hline \multicolumn{8}{|l|}{ 3. Stable } \\
\hline & \multicolumn{7}{|l|}{ Men } \\
\hline & & Black & $30-39$ & 1999-2015 & $-0.2(-1.5,1.1)$ & & \\
\hline & & White & $40-49$ & 1999-2015 & $-0.5(-4.5,3.6)$ & & \\
\hline & & White & $50-59$ & 1999-2015 & $-0.1(-2.6,2.5)$ & & \\
\hline & & White & $60-69$ & 1999-2015 & $0.4(-1.2,2)$ & & \\
\hline & \multicolumn{7}{|c|}{ Women } \\
\hline & & Black & $30-39$ & 1999-2015 & $-0.2(-1.9,1.6)$ & & \\
\hline & & Black & $70+$ & 1999-2015 & $-0.1(-1.2,1)$ & & \\
\hline & & White & $40-49$ & 1999-2015 & $-0.2(-8.9,9.2)$ & & \\
\hline \multicolumn{8}{|c|}{ 4. Non-significant Increase } \\
\hline & \multicolumn{7}{|l|}{ Men } \\
\hline & & Black & $50-59$ & 1999-2010 & $-3.7^{*}(-5.3,-2.2)$ & 2010-2015 & $5.4(-0.1,11.2)$ \\
\hline & & Black & $60-69$ & 1999-2009 & $-5.2^{*}(-7.3,-3)$ & 2009-2015 & $2.5(-2.4,7.6)$ \\
\hline \multicolumn{8}{|c|}{ 5. Significant Increase } \\
\hline & \multicolumn{7}{|c|}{ Women } \\
\hline & & Black & $50-59$ & 1999-2004 & $-5.2(-10.4,0.4)$ & 2004-2015 & $2.6^{*}(0.8,4.4)$ \\
\hline & & Black & $60-69$ & 1999-2009 & $-4.9^{*}(-6.9,-2.8)$ & 2009-2015 & $6.3^{*}(1.5,11.3)$ \\
\hline
\end{tabular}

*The annual percent change (APC) is statistically significant $(p<0.05)$

these services and the better application of early detection strategies, other factors may impede the ability to seek and obtain timely services [18]. For example, evidence from earlier studies in SA show that the bottom segment of the distributions in income [19], education/ literacy [20], dependence on public health care programs [21] are dominated by black Africans and health insurance coverage shares are far from proportionate with population shares $(73.3 \%$ and $10.6 \%$ of white and black Africans with health insurance in 2015, respectively)
[20]. In a study in SA, the authors reported that of the 22 patients with $\mathrm{HCC}$ who received surgical treatment, the surgical rates were lower for black Africans [22]. While it is possible that cultural beliefs and attitudes may have impacted on the appropriate treatment decision-making [23], other reports have attributed this disparity to differences in the biology and presentation of the disease [24-26]. Previous studies have suggested that black Africans are more likely to be diagnosed symptomatically in the absence of any screening 


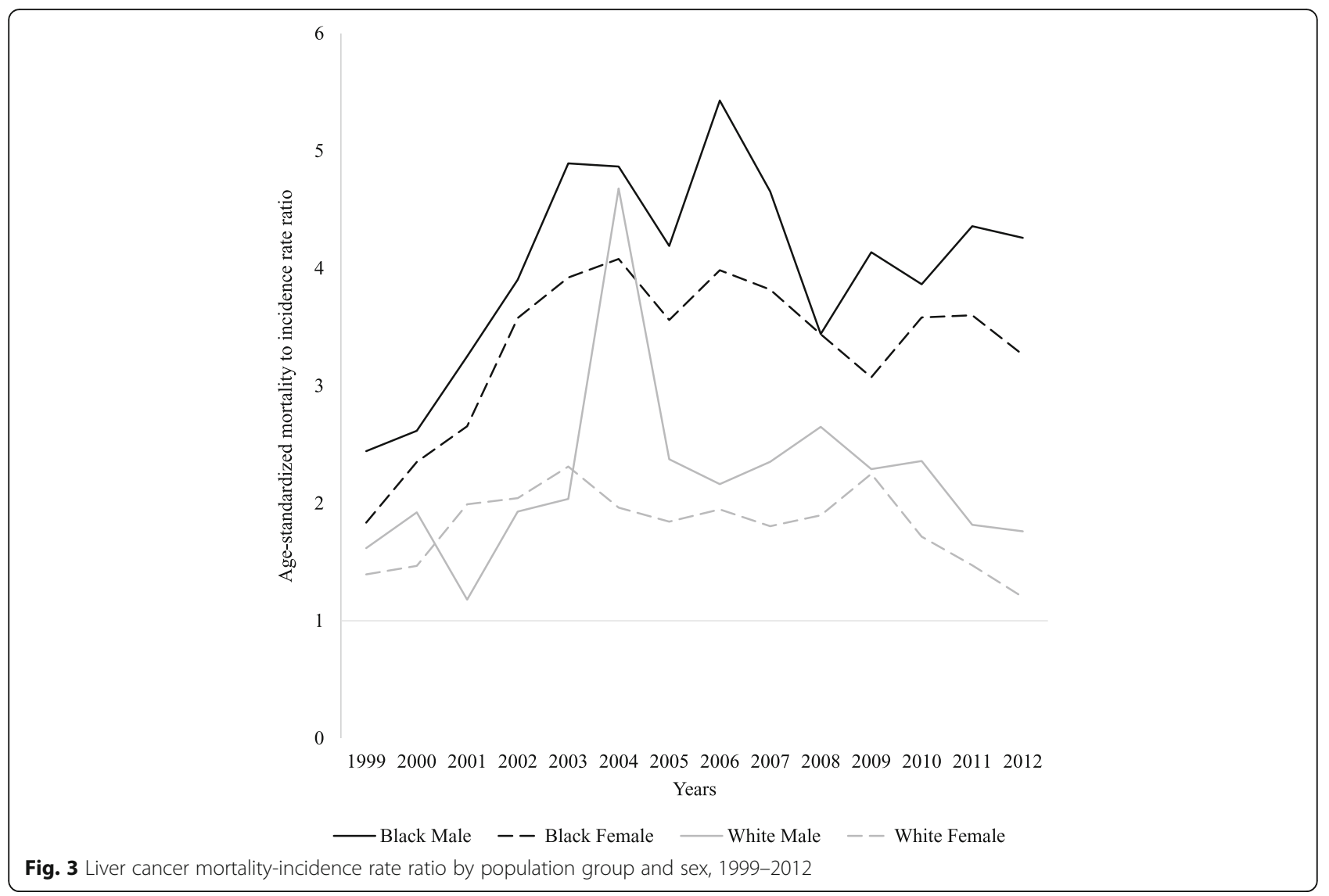

methods, at a later stage of disease with larger tumours (80-90\%) [24, 25], and when curative treatments are no longer feasible [26].

Alternatively, changes in the prevalence of risk factors may play a role. For example it is well recognized that HBV is a primary risk factor and its prevalence differs among black Africans (4-16\%) and whites (0.2\%) in the same manner as does the burden of LC in SA [27, 28]. While the vaccine against HBV has been shown to be efficacious at reducing $\mathrm{HBV}$ infections, and ultimately HCC, among vaccinated cohorts of children [29, 30], they remain ineffective for most chronically infected adults born prior to its incorporation into the Expanded Programme on Immunisation in 1995. Comparisons of a study in the 1990s [31] to that of the 2000s [32] showed that $\mathrm{HBV}$-infected HCC cases are generally diagnosed in their 30s, and the HBsAg rates in HCC patients have increased in men $(38.2 \%$ versus $43.2 \%$, respectively) and women $(24.1 \%$ versus $35.9 \%$, respectively). In contrast, $\mathrm{HCV}$ infection is relatively uncommon in SA $(0.75 \%$ and $0.16 \%$ in black Africans and whites, respectively) [33], but affects older patients who are in their 50s [31]. Unlike HBV infection, HCV-positivity in HCC patients decreased (28.7\% versus $5.4 \%$ ) from the $1990 \mathrm{~s}$ [31] to 2000s [32].
Data on other potential factors associated with lifestyle behaviours (obesity, diabetes, alcohol consumption and dietary exposure to aflatoxin) influencing LC rates are limited in SA, with our recent study showing minimal effects [32]. Thus it is difficult to determine which of these factors predominantly influenced the trends in LC burden, because the population attributable fraction of these factors is not as large as hepatitis infection. Future studies should explore the impact of these aetiological factors on LC mortality and incidence at an individual level.

In $\mathrm{SA}$, it is clear that human immuno-deficiency virus (HIV) epidemic has had a major demographic and health impact particularly in black African population. Findings from previous studies from SA and Uganda that have failed to show increases in HCC risk among HIV-infected persons through the pre-ART years (pre-2004 in SA), possibly as a result of the competing risks of AIDS-related deaths [34, 35]. However, an increase in LC cases has been noted in the ART era in developed countries [36]. Our results show an upswing in LC mortality rates in black Africans during the inception of ART in 2004 [37] (number of adults accessing ART was 4.9\%) [38] and the massively scaled up program in 2009 (61\%) [39]. In Uganda, a study reported that with each 
$10 \%$ increase in ART coverage, LC incidence increased by $12 \%$ [40]. It has been suggested that the change in the spectrum of liver disease is shifting from opportunistic infections to sequelae of chronic $\mathrm{HBV} / \mathrm{HCV}$ infections, medication toxicities, alcoholism, and fatty liver [41], possibly as a result of increased longevity. Although these associations need to be further investigated in SA, it is conceivable that results presented here may be interpreted as revealing an effect of ART given that both the number of people in SA living with HIV, and those with access to ART are among the highest in the world [42]. Findings from this study raise considerable concern that the burden of LC may expand concurrently with the implementation of an universal ART eligibility to all 7.1 million HIV-positive South Africans from 2016 [43], further highlighting the need for a comprehensive program focused on population-based cancer surveillance and control including LC in SA [44].

In a region characterized by the poor surveillance systems, tracking the emerging trends in the death rates is an essential tool to assist with cancer-control planning, early detection, and prevention efforts. Additionally, because preventing deaths must be an important part of any competent cancer prevention and control effort, the statistics described in this study also address an important need - to describe and highlight the knowledge gap of LC mortality in relation to incidence. The MIRs of LC in men and women in our study (black African: 4 and 3.3; white: 2.2 and 1.8 , respectively) was significantly great compared that reported in another HBV endemic region, China (0.91 and 0.92, respectively) [45]. Given the high MIR ratios reported in our study, pathology-based cancer registration is inadequate to characterise LC epidemiology in SA. The establishment of a nationally representative population-based cancer registration should be a priority for cancer control in SA as it will capture cases of LC diagnosed clinically and radiologically in addition to laboratory based diagnoses.

Several potential limitations should be acknowledged. There have been considerable improvements in the national coverage and completeness of death registration, but shortcomings of the quality of death certification have been suggested in ill-defined and misattributed causes of single-cause data [46]. Considering that the liver is a frequent site of cancer metastasis, cause of death determination using death certificates may result in false-positives in the absence of biopsy [47]. Additionally, failure or under-ascertainment of cause-of-death could lead to bias in death registration, particularly in resource-limited regions [39]. Despite regular census data being available, concerns about the accuracy of earlier population estimates may suggest the possible introduction of uncertainty in estimated mortality rates [12]. The number of LC-related deaths may be overestimated because StatsSA collects and processes death information irrespective of the deceased's citizenship. The livelihood conditions in SA make it an attractive destination for migration and therefore cross border migrations are frequent [48]. On the other hand, the inability of the SA health-system to meet the health needs of the migrants means that when their health deteriorates they return to their place of origin to seek healthcare and support [49]. Trends analyses on LC rates in the current study were descriptive analyses at population levels without inference at individual levels. Because data at individual level on socioeconomic status and various potential confounders were not available, interpretations from the results do not necessarily hold true for individuals.

\section{Conclusion}

In summary, this is the first study to estimate the total burden of liver cancer deaths in SA. Our results indicate a rising trend for this disease in middle to older aged black African men and women in the recent decade. The reasons for this are likely manifold, but may be a consequence of improved life expectancy and rising prevalence of risk factors related to lifestyle behaviours. Further research into the aetiologic factors contributing to population-age sub-group mortality patterns are needed, to provide informative interventions to curb the rising burden of liver cancer deaths and to reduce the population group disparities. Our findings may be used to inform national health and social development policies in SA and other regions of southern Africa.

\begin{abstract}
Abbreviations
AAPC: Average annual percentage change; APC: Annual percentage change; ASIR: Age-standardized incidence rate; ASMR: Age-standardized mortality rate; HBV: Hepatitis B virus; HCC: Hepatocellular carcinoma; HCV: Hepatitis C virus; HIV: Human immuno-deficiency virus; LC: Liver Cancer; MIR: Mortality-to-incidence ratio; SA: South Africa; StatsSA: Statistics South Africa
\end{abstract}

\section{Acknowledgements}

We acknowledge South African National Cancer Registry and Statistics South Africa for providing the data with special permission for use.

\section{Funding}

DWM: This work was supported by the Deutsche Forschungsgemeinschaft (DFG) grant (GL 595/3-1) and Cancer Association of South Africa, who had no involvement in conduct of the research and/or preparation of the article.

\section{Availability of data and materials}

The datasets supporting the conclusions of this article are available in the Statistics South Africa and South African National Cancer Registry repository, [http://www.statssa.gov.za (upon request) and http://www.nicd.ac.za/ index.php/centres/national-cancer-registry/, respectively].

\section{Authors' contributions}

DM has been involved in all stages of the study including the conception and design of the study, literature review, data management and analysis, data interpretation, and the writing, review and/or revision of the manuscript. MS and WCC were involved in the acquisition of the data, data interpretation and the critical review and revision of the manuscript. CBdV initiated the research idea and was involved in the data interpretation critical review and revision of the manuscript. AK and ES were involved in the study 
supervision, data interpretation critical review and revision of the manuscript. All authors gave final approval of the version to be published.

\section{Ethics approval and consent to participate}

Ethical approval (\#M150239) was obtained from the Human Research Ethics

Committee (Medical), the University of Witwatersrand, Johannesburg, South Africa.

\section{Consent for publication}

Not applicable.

\section{Competing interests}

The authors declare that they have no competing interests.

\section{Publisher's Note}

Springer Nature remains neutral with regard to jurisdictional claims in published maps and institutional affiliations.

\section{Author details}

${ }^{1}$ Hepatitis Virus Diversity Research Unit (HVDRU), Department of Internal Medicine, School of Clinical Medicine, Faculty of Health Sciences, University of Witwatersrand, Johannesburg, South Africa. ${ }^{2}$ National Cancer Registry, National Health Laboratory Service, Johannesburg, South Africa. ${ }^{3}$ School of Public Health, University of the Witwatersrand, Johannesburg, South Africa. ${ }^{4}$ Division of Human Genetics, School of Pathology, Faculty of Health Sciences, University of the Witwatersrand, Johannesburg, South Africa. ${ }^{5}$ Sydney Brenner Institute for Molecular Bioscience, University of the Witwatersrand, Johannesburg, South Africa.

Received: 16 February 2018 Accepted: 26 July 2018

Published online: 07 August 2018

\section{References}

1. Ferlay J, Soerjomataram I, Dikshit R, Eser S, Mathers C, Rebelo M, Parkin DM, Forman D, Bray F. Cancer incidence and mortality worldwide: sources, methods and major patterns in GLOBOCAN 2012. Int J Cancer. 2015;136(5): E359-86.

2. Akinyemiju T, Abera S, Ahmed M, Alam N, Alemayohu MA, Allen C, AlRaddadi R, Alvis-Guzman N, Amoako Y, Artaman A. The burden of primary liver cancer and underlying etiologies from 1990 to 2015 at the global, regional, and national level: results from the global burden of disease study 2015. JAMA Oncol. 2017;3(12):1683-91.

3. Center MM, Jemal A. International trends in liver cancer incidence rates. Cancer Epidemiol Biomark Prev. 2011;20(11):2362-8.

4. Altekruse SF, Henley SJ, Cucinelli JE, McGlynn KA. Changing hepatocellular carcinoma incidence and liver cancer mortality rates in the United States. Am J Gastroenterol. 2014;109(4):542.

5. Islami F, Miller KD, Siegel RL, Fedewa SA, Ward EM, Jemal A. Disparities in liver cancer occurrence in the United States by race/ethnicity and state. CA A Cancer J Clin. 2017:67(4):273-289.

6. McGlynn KA, Tarone RE, El-Serag HB. A comparison of trends in the incidence of hepatocellular carcinoma and intrahepatic cholangiocarcinoma in the United States. Cancer Epidemiol Biomark Prev. 2006;15(6):1198-203.

7. Xu L, Kim Y, Spolverato G, Gani F, Pawlik TM. Racial disparities in treatment and survival of patients with hepatocellular carcinoma in the United States. Hepatobiliary Surg Nutr. 2015;5(1):43-52

8. Sloane $\mathrm{D}$, Chen $\mathrm{H}$, Howell C. Racial disparity in primary hepatocellular carcinoma: tumor stage at presentation, surgical treatment and survival. J Natl Med Assoc. 2006:98(12):1934

9. Flores YN, Yee HF Jr, Leng M, Escarce JJ, Bastani R, Salmerón J, Morales LS. Risk factors for chronic liver disease in Blacks, Mexican Americans, and Whites in the United States: results from NHANES IV, 1999-2004. Am J Gastroenterol. 2008;103(9):2231.

10. Singh GK, Jemal A. Socioeconomic and racial/ethnic disparities in cancer mortality, incidence, and survival in the United States, 1950-2014: over six decades of changing patterns and widening inequalities. J Environ Public Health. 2017;2017: 19 pages.

11. Lehohla P. Census 2011: Population dynamics in South Africa, Statistics South Africa. 2015: 1-112.

12. StatsSA. Mid-year population estimates 2015. In: P0302. Pretoria: Statistics South Africa; 2015: 20 pages.
13. Segi M. Cancer mortality for selected sites in 24 countries: (1964-1965). Department of Public Health Tohoku University School of Medicine; 1969.

14. Kim H-J, Fay MP, Feuer EJ, Midthune DN. Permutation tests for joinpoint regression with applications to cancer rates. Stat Med. 2000;19(3):335-51.

15. Health UNIon. Cancer trends progress report-2011/2012 update. Bethesda: National Cancer Institute; 2012. p. 19.

16. Joinpoint Regression Program, Version 4.5.0.1 - June 2017; Statistical Methodology and Applications Branch, Surveillance Research Program, National Cancer Institute. http://surveillance.cancer.gov/joinpoint/. Accessed 20 June 2017.

17. Nteta TP, Mokgatle-Nthabu M, Oguntibeju OO. Utilization of the primary health care services in the Tshwane region of Gauteng Province, South Africa. PLoS One. 2010:5(11):e13909.

18. Kon ZR, Lackan N. Ethnic disparities in access to care in post-apartheid South Africa. Am J Public Health. 2008:98(12):2272-7.

19. Leibbrandt M, Woolard I, Finn A, Argen J: Trends in South African income distribution and poverty since the fall of apartheid. 2010

20. StatsSA: General household survey 2012: Statistics South Africa Stats release P0318; 2012.

21. Wadee H, Gilson L, Thiede M, Okorafor O, Mclntyre D: Health care inequity in South Africa and the public-private mix. 2003.

22. Bhaijee F, Krige J, Locketz M, Kew M. Liver resection for non-cirrhotic hepatocellular carcinoma in South African patients. S Afr J Surg. 2011:49(2):68-74.

23. Mullin VC, Cooper SE, Eremenco S. Communication in a South African cancer setting: cross-cultural implications. Int J Rehabil Health. 1998;4(2):69-82.

24. Kew MC. Clinical, pathologic, and etiologic heterogeneity in hepatocellular carcinoma: evidence from southern Africa. Hepatology. 1981;1(4):366-9.

25. Kew MC. Hepatocellular carcinoma with and without cirrhosis. Gastroenterology. 1989;97(1):136-9.

26. Ladep NG, Lesi OA, Mark P, Lemoine M, Onyekwere C, Afihene M, Crossey MM, Taylor-Robinson SD. Problem of hepatocellular carcinoma in West Africa. World J Hepatol. 2014:6(11):783.

27. Kew MC. Hepatitis B virus infection: the burden of disease in South Africa. South Afr J Epidemiol Infect. 2008;23(1):4-8.

28. Kew M, Song E, Dusheiko G. Hepatocellular carcinoma in white South Africans--aetiological considerations. S Afr Med J. 1984:66(22):835-7.

29. Bhimma R, Coovadia HM, Adhikari M, Connolly CA. The impact of the hepatitis $B$ virus vaccine on the incidence of hepatitis $B$ virus-associated membranous nephropathy. Arch Pediatr Adolesc Med. 2003;157(10):1025-30.

30. Moore S, Davidson A, Hadley G, Kruger M, Poole J, Stones D, Wainwright L, Wessels G. Malignant liver tumors in South African children: a national audit. World J Surg. 2008;32(7):1389-95.

31. Kew M, Houghton M, Choo Q, Kuo G. Hepatitis C virus antibodies in southern African blacks with hepatocellular carcinoma. Lancet. 1990;335(8694):873-4.

32. Mak D, de Villiers CB, Chasela C, Urban MI, Kramvis A. Analysis of risk factors associated with hepatocellular carcinoma in black South Africans: 2000-2012. PLOS One. 2018:13(5):e0196057.

33. Barth RE, Huijgen Q, Tempelman HA, Mudrikova T, Wensing AM, Hoepelman Al. Presence of occult HBV, but near absence of active HBV and HCV infections in people infected with HIV in rural South Africa. J Med Virol. 2011:83(6):929-34

34. Stein L, Urban Ml, O'Connell D, Yu XQ, Beral V, Newton R, Ruff P, Donde B, Hale M, Patel M. The spectrum of human immunodeficiency virusassociated cancers in a South African black population: results from a casecontrol study, 1995-2004. Int J Cancer. 2008:122(10):2260-5.

35. Mbulaiteye SM, Katabira ET, Wabinga H, Parkin DM, Virgo P, Ochai R, Workneh M, Coutinho A, Engels EA. Spectrum of cancers among HIVinfected persons in Africa: the Uganda AIDS-Cancer Registry Match Study. Int J Cancer. 2006;118(4):985-90.

36. Engels EA, Biggar RJ, Hall HI, Cross H, Crutchfield A, Finch JL, Grigg R, Hylton T, Pawlish KS, McNeel TS. Cancer risk in people infected with human immunodeficiency virus in the United States. Int J Cancer. 2008;123(1):187-94.

37. Draper B, Abdullah F. A review of the prevention of mother-to-child transmission programme of the Western Cape provincial government, 2003-2004. S Afr Med J. 2008;98(6):431-4.

38. Adam MA, Johnson LF. Estimation of adult antiretroviral treatment coverage in South Africa: original article. S Afr Med J. 2009;99(9):661-7.

39. Klausner JD, Serenata C, O'bra H, Mattson CL, Brown J, Wilson M, Mbengashe T, Goldman TM. Scale-up and continuation of antiretroviral therapy in South African treatment programs, 2005-2009. J Acquir Immune Defic Syndr. 2011;56(3):292-5 
40. Mutyaba I, Phipps W, Krantz EM, Goldman JD, Nambooze S, Orem J, Wabinga HR, Casper C. A population-level evaluation of the effect of antiretroviral therapy on cancer incidence in Kyadondo County, Uganda, 1999-2008. J Acquir Immune Defic Syndr. 2015:69(4):481.

41. Price JC, Thio CL. Liver disease in the HIV-infected individual. Clin Gastroenterol Hepatol. 2010;8(12):1002-12

42. Joint United Nations Programme on HIV and AIDS (UNAIDS). 2015 HIV and AIDS estimates. http://www.unaids.org/en/regionscountries/countries/ southafrica. Accessed Jan 2018.

43. Cornell M, Johnson LF, Wood R, Tanser F, Fox MP, Prozesky H, Schomaker M, Egger M, Davies MA, Boulle A. Twelve-year mortality in adults initiating antiretroviral therapy in South Africa. J Int AIDS Soc. 2017;20(1):21902

44. Singh E, Ruff P, Babb C, Sengayi M, Beery M, Khoali L, Kellett P, Underwood $J$ M. Establishment of a cancer surveillance programme: the South African experience. Lancet Oncol. 2015;16(8)::414-21.

45. Wei K-R, Yu X, Zheng R-S, Peng X-B, Zhang S-W, Ji M-F, Liang Z-H, Ou Z-X, Chen W-Q. Incidence and mortality of liver cancer in China, 2010. Chin J Cancer. 2014;33(8):388.

46. Joubert J, Rao C, Bradshaw D, Vos T, Lopez AD. Evaluating the quality of national mortality statistics from civil registration in South Africa, 1997-2007. PLoS One. 2013;8(5):e64592.

47. Sharp GB, Cologne JB, Fukuhara T, Itakura H, Yamamoto M, Tokuoka S. Temporal changes in liver cancer incidence rates in Japan: accounting for death certificate inaccuracies and improving diagnostic techniques. Int J Cancer. 2001;93(5):751-8.

48. StatsSA. Community Survey 2016. Pretoria: Statistics South Africa; 2016

49. Ginsburg C, Bocquier P, Béguy D, Afolabi S, Augusto O, Derra K, Herbst K, Lankoande B, Odhiambo F, Otiende M. Healthy or unhealthy migrants? Identifying internal migration effects on mortality in Africa using health and demographic surveillance systems of the INDEPTH network. Soc Sci Med. 2016;164:59-73.

Ready to submit your research? Choose BMC and benefit from:

- fast, convenient online submission

- thorough peer review by experienced researchers in your field

- rapid publication on acceptance

- support for research data, including large and complex data types

- gold Open Access which fosters wider collaboration and increased citations

- maximum visibility for your research: over $100 \mathrm{M}$ website views per year

At $\mathrm{BMC}$, research is always in progress.

Learn more biomedcentral.com/submissions 